\title{
A user's guide to the human genome
}

\author{
doi:10.1038/ng1187
}

The primary aim of $A$ User's Guide to the Human Genome is to provide the reader with an elementary hands-on guide for browsing and analyzing data produced by the International Human Genome Sequencing Consortium and other systematic sequencing efforts. The majority of this supplement is devoted to a series of worked examples, providing an overview of the types of data available, details on how these data can be browsed, and stepby-step instructions for using many of the most commonly-used tools for sequence-based discovery. The major web portals featured throughout include the National Center for Biotechnology Information Map Viewer, the University of California, Santa Cruz Genome Browser, and the European Bioinformatics Institute's Ensembl system, along with many others that are discussed in the individual examples. It is hoped that readers will become more familiar with these resources, allowing them to apply the strategies used in the examples to advance their own research programs.

\section{Authors}

Tyra G. Wolfsberg

Kris A. Wetterstrand

Mark S. Guyer

Francis S. Collins

Andreas D. Baxevanis

National Human Genome Research Institute, National Institutes of Health, Bethesda, Maryland 20892, USA. e-mail:andy@nhgri.nih.gov 